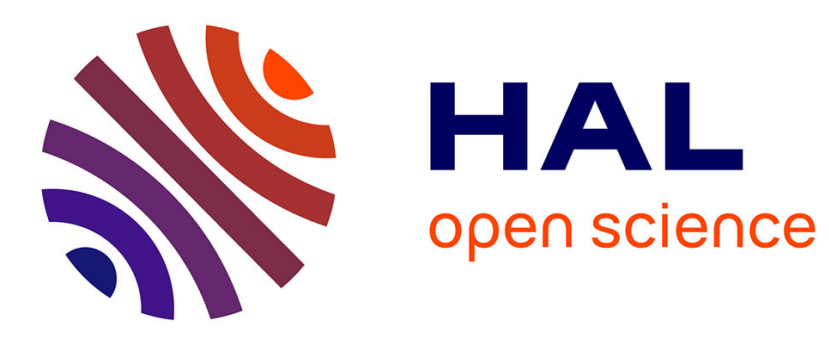

\title{
Airglow observations of orographic, volcanic and meteorological infrasound signatures
}

Christoph Pilger, Carsten Schmidt, Florian Streicher, Sabine Wüst, Michael Bittner

\section{- To cite this version:}

Christoph Pilger, Carsten Schmidt, Florian Streicher, Sabine Wüst, Michael Bittner. Airglow observations of orographic, volcanic and meteorological infrasound signatures. Journal of Atmospheric and Solar-Terrestrial Physics, 2013, 104, pp.55-66. 10.1016/j.jastp.2013.08.008 . hal-02091361

\section{HAL Id: hal-02091361 https://hal.science/hal-02091361}

Submitted on 5 Apr 2019

HAL is a multi-disciplinary open access archive for the deposit and dissemination of scientific research documents, whether they are published or not. The documents may come from teaching and research institutions in France or abroad, or from public or private research centers.
L'archive ouverte pluridisciplinaire HAL, est destinée au dépôt et à la diffusion de documents scientifiques de niveau recherche, publiés ou non, émanant des établissements d'enseignement et de recherche français ou étrangers, des laboratoires publics ou privés. 


\title{
Airglow observations of orographic, volcanic and meteorological infrasound signatures
}

\author{
Christoph Pilger ${ }^{a, b, *}$, Carsten Schmidt ${ }^{c}$, Florian Streicher ${ }^{c}$, Sabine Wüst ${ }^{c}$, \\ Michael Bittner ${ }^{\mathrm{b}, \mathrm{c}}$ \\ ${ }^{a}$ Federal Institute for Geosciences and Natural Resources (BGR), 30655 Hannover, Germany \\ ${ }^{\mathrm{b}}$ Augsburg University (UNA), 86135 Augsburg, Germany

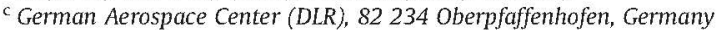

\begin{abstract}
A B S T R A C T
Infrasound is generated by several different natural hazards as, e.g., volcanic eruptions and severe weather, but also due to orography (flow over mountains) or anthropogenic sources (e.g. explosions). It propagates from the surface to the middle and upper atmosphere, is characterized by pressure and temperature fluctuations on its path and is reflected back to the ground in so-called ducts. The effects of infrasound in terms of temperature fluctuations in the middle atmosphere, especially in the mesopause altitude region ( $80-100 \mathrm{~km}$ ), can be observed using ground-based airglow spectrometers as, e.g., the GRIPS (GRound-based Infrared P-branch Spectrometers) instruments of the German Aerospace Center (DLR).

A method to identify and spectrally analyse infrasound signatures in mesopause temperature time series derived from nocturnal GRIPS airglow observations is presented. The automatic identification of spectral features in the observations and association to distinct infrasound sources is described. Source verification is performed by considering weather situations, volcanic activity and infrasound propagation modelling.

The results in terms of identified infrasound sources of orographic, volcanic and meteorological origin are presented and discussed for a number of different case studies.
\end{abstract}

\section{Introduction}

Airglow observations of orographic, volcanic and meteorological infrasound signatures have been performed within a project of the Bavarian State Ministry for Environment and Health called CESAR ("Charakterisierung des differentiellen Energiegehaltes von VbZyklonen über die Quantifizierung abgestrahlter Schwere- und Infraschallwellen in der Atmosphäre", translated: characterization of the differential energy content of $\mathrm{Vb}$ cyclones by quantifying emitted gravity and infrasonic waves in the atmosphere). The quantification of gravity wave and infrasound activity of Mediterranean storm systems and the characterization of their differential energy content have been performed to improve the medium-range forecast of severe weather events and storm tracks. The emission of atmospheric waves by the convective activity of thunderstorms, frontal passages and cyclones has been investigated to distinguish these signatures from other natural or anthropogenic wave

\footnotetext{
* Corresponding author at: Federal Institute for Geosciences and Natural Resources (BGR), 30655 Hannover, Germany. Tel.: +49511 6432878 .

E-mail address: christoph.pilger@bgr.de (C. Pilger).
}

signatures and thus to identify and quantify severe weather activity in the vicinity of the different measurement sites.

Data from airglow measurements, radiosonde ascents and satellite observations have been analysed within the project to derive infrasound and gravity wave features with a set of different spectral analysis techniques. An automatic procedure for the analysis of airglow observations, identification of potential wave signatures and verification of associated infrasound sources is presented within this study.

Infrasonic waves are sub-audible sound waves with frequencies of 20 to $0.003 \mathrm{~Hz}$ corresponding to periods between 0.05 and $300 \mathrm{~s}$ (see e.g. Le Pichon et al, 2010 for a recent and comprehensive overview on infrasound topics). Infrasound is generated by a variety of different sources of natural or anthropogenic origin as, e.g., earthquakes, volcanic activity, aurora, severe weather and manmade explosions (see e.g. Gossard and Hooke, 1975; Blanc, 1985). Infrasonic waves are small-scale pressure fluctuations which propagate over long distances in the atmosphere following certain propagation patterns described, e.g., by ray-tracing methods (see Drob et al., 2003; Jones et al., 2004; Pilger and Bittner, 2009). Infrasound effects can be observed in situ, e.g., by high resolution surface pressure measurements of microphones or microbarometer 
arrays (see Le Pichon et al., 2009; Christie and Campus, 2010) and also by remote sensing techniques observing atmospheric temperature or ionospheric electron density variations with high temporal resolution (see Bittner et al., 2010; Sindelarova et al., 2009). Therefore, infrasound is also observable in temperature time series derived from airglow intensity observations of the mesopause altitude $(80-100 \mathrm{~km})$.

The airglow emission (see Khomich et al., 2008 and references therein) is electromagnetic radiation in the visible and infrared spectrum, generated by the de-excitation of atoms and molecules concentrated in certain layers of the atmosphere. The most prominent airglow originates from a layer of hydroxyl $(\mathrm{OH})$ molecules with a half width of approximately $4 \mathrm{~km}$ centred in around $87 \mathrm{~km}$ altitude, in the mesopause altitude region. The $\mathrm{OH}$ airglow emission can be observed by ground-based infrared spectrometers as, e.g., the GRIPS (GRound-based Infrared P-branch Spectrometers) instruments used within this study (see Bittner et al., 2010; Schmidt et al., 2013).

The identification and discrimination of infrasound by different sources in airglow measurements is illustrated in exemplary observations in the course of this paper. Considered infrasonic sources are mountain-associated waves, volcanic eruptions and severe weather sources.
The paper is organized as follows: details of airglow observations are described in Section 2. A combination of spectral analysis techniques and source verification methods for infrasound signal detection is elaborated in Section 3. Results in terms of example cases for orographic, volcanic and meteorological infrasound signatures are presented and discussed in Section 4. Section 5 gives a final summary and outlook.

\section{Observation method}

Airglow observations are performed using infrared spectrometers observing the nocturnal hydroxyl $(\mathrm{OH}-)$ emission originating from an altitude layer of about $87 \pm 4 \mathrm{~km}$, located in the mesopause altitude region of the middle atmosphere (height of $\sim 80-100 \mathrm{~km})$. The airglow emission in terms of visible and infrared radiation is generated by the rotational-vibrational relaxation of excited $\mathrm{OH}$-molecules formed by an exothermic reaction of ozone and atomic hydrogen (see e.g. Bates and Nicolet, 1950; Baker and Stair, 1988). The intensity of the $\mathrm{OH}$ emissions can be used to derive rotational temperatures, which are a good tracer for the actual kinetic temperature in the emission altitude (see Meinel, 1950; Pendleton et al., 1993). Time series of
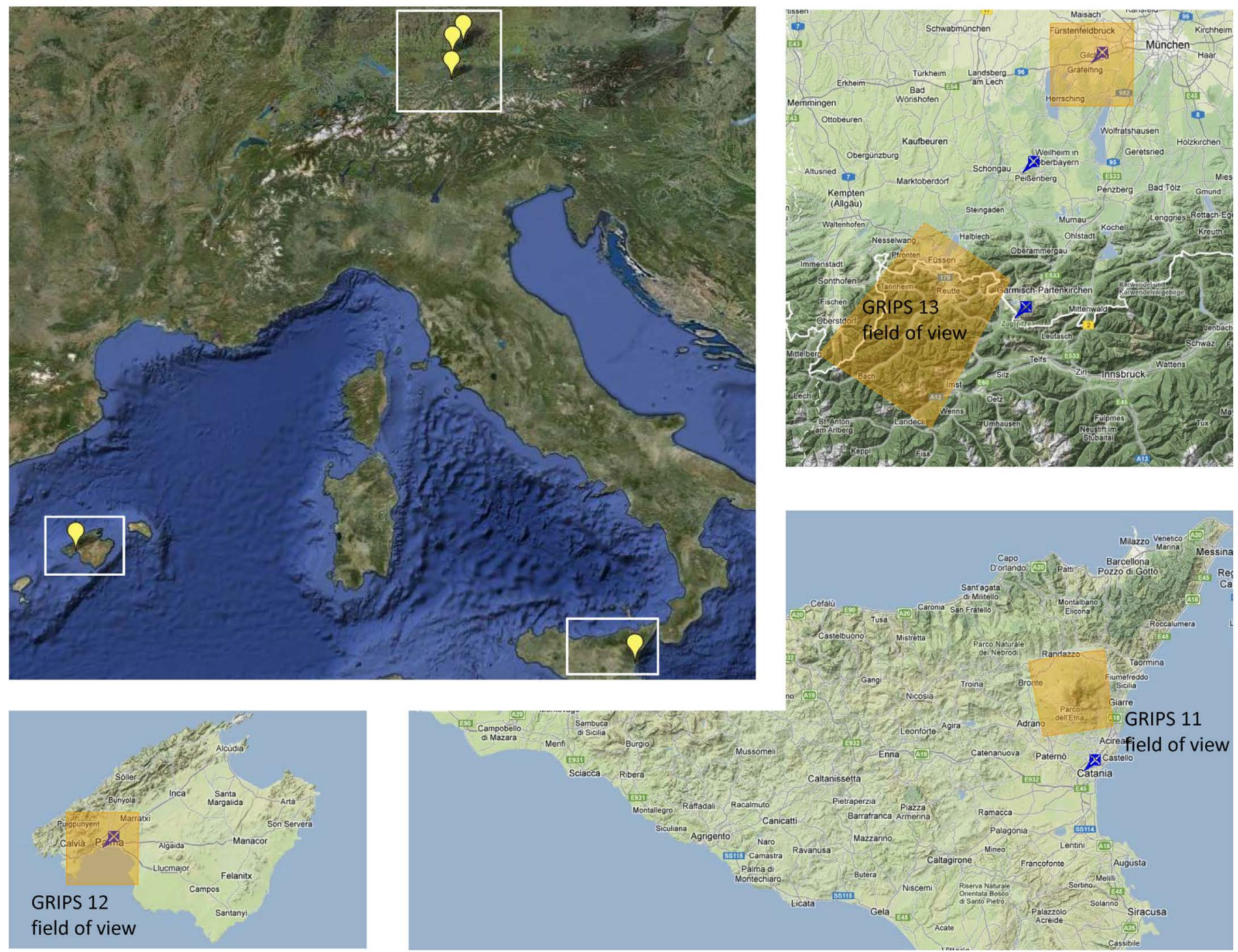

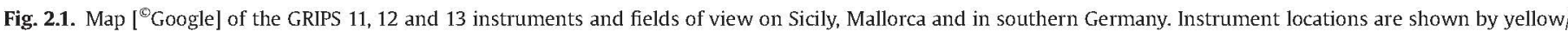

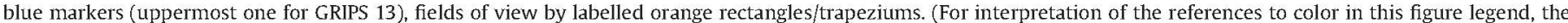
reader is referred to the web version of this article.) 
such derived mesopause temperatures are used within this study to identify and distinguish wave signatures generated by different sources of atmospheric or near-surface origin.

The airglow observations within this study are performed using GRIPS instruments (see Bittner et al., 2010; Schmidt et al., 2013) of the German Aerospace Center (DLR) deployed at different sites in Europe. The GRIPS 11 instrument was installed in September 2011 in Catania, Italy, in cooperation with the Istituto Nazionale di Geofisica e Vulcanologia (INGV, Italy). The GRIPS 12 instrument performed measurements at Palma de Mallorca, Spain, during a campaign from September 2011 to January 2012 in cooperation with the Agencia Estatal de Meteorología (AEMET, Spain). The GRIPS 13 instrument located at the DLR Oberpfaffenhofen, Germany, performs high temporal resolution measurements since April 2012. The location of the GRIPS instruments and their field of view is shown in Fig. 2.1, relevant information about the instruments and their technical details are described in Table 2.1. The GRIPS instruments are part of the Network for the Detection of Mesosphere Change (NDMC), a global network for airglow and associated observations within the mesosphere and mesopause altitude (see http://wdc.dlr.de/ndmc/).

\section{Analysis technique}

Temperature time series derived from GRIPS airglow observations are spectrally analysed with the aim of identifying and discriminating infrasonic wave signatures in these measurements. The algorithm used for the recognition of wave patterns in GRIPS temperature time series consists of a combination of spectral

Table 2.1

Technical details of the GRIPS 11,12 and 13 instruments used within this study.

\begin{tabular}{|c|c|c|c|}
\hline Instrument & GRIPS 11 & GRIPS 12 & GRIPS 13 \\
\hline Station & CAT (Catania) & PAL (Palma de Mallorca) & OPN (Oberpfaffenhofen) \\
\hline Coordinates & $15.04^{\circ} \mathrm{E}, 37.51^{\circ} \mathrm{N}$ & $2.63^{\circ} \mathrm{E}, 39.55^{\circ} \mathrm{N}$ & $11.27^{\circ} \mathrm{E}, 48.08^{\circ} \mathrm{N}$ \\
\hline Measurement period & since 27.09 .2011 & 13.09.2011-10.01.2012 (119 nights of observation) & since 31.03 .2012 \\
\hline Temporal resolution & $15 \mathrm{~s}$ & $15 \mathrm{~s}$ & $5 \mathrm{~s}$ \\
\hline Aperture & $2.5^{\circ} \times 2.5^{\circ}$ & $15.5^{\circ} \times 15.5^{\circ}$ & $15.5^{\circ} \times 15.5^{\circ}$ \\
\hline Observation geometry & $\begin{array}{l}\text { oblique (zenith angle } 17^{\circ} \text {, centred } \\
\text { above Mt. Etna volcano) }\end{array}$ & zenithal (zenith angle $0^{\circ}$ ) & oblique (zenith angle $66^{\circ}$ ) \\
\hline
\end{tabular}

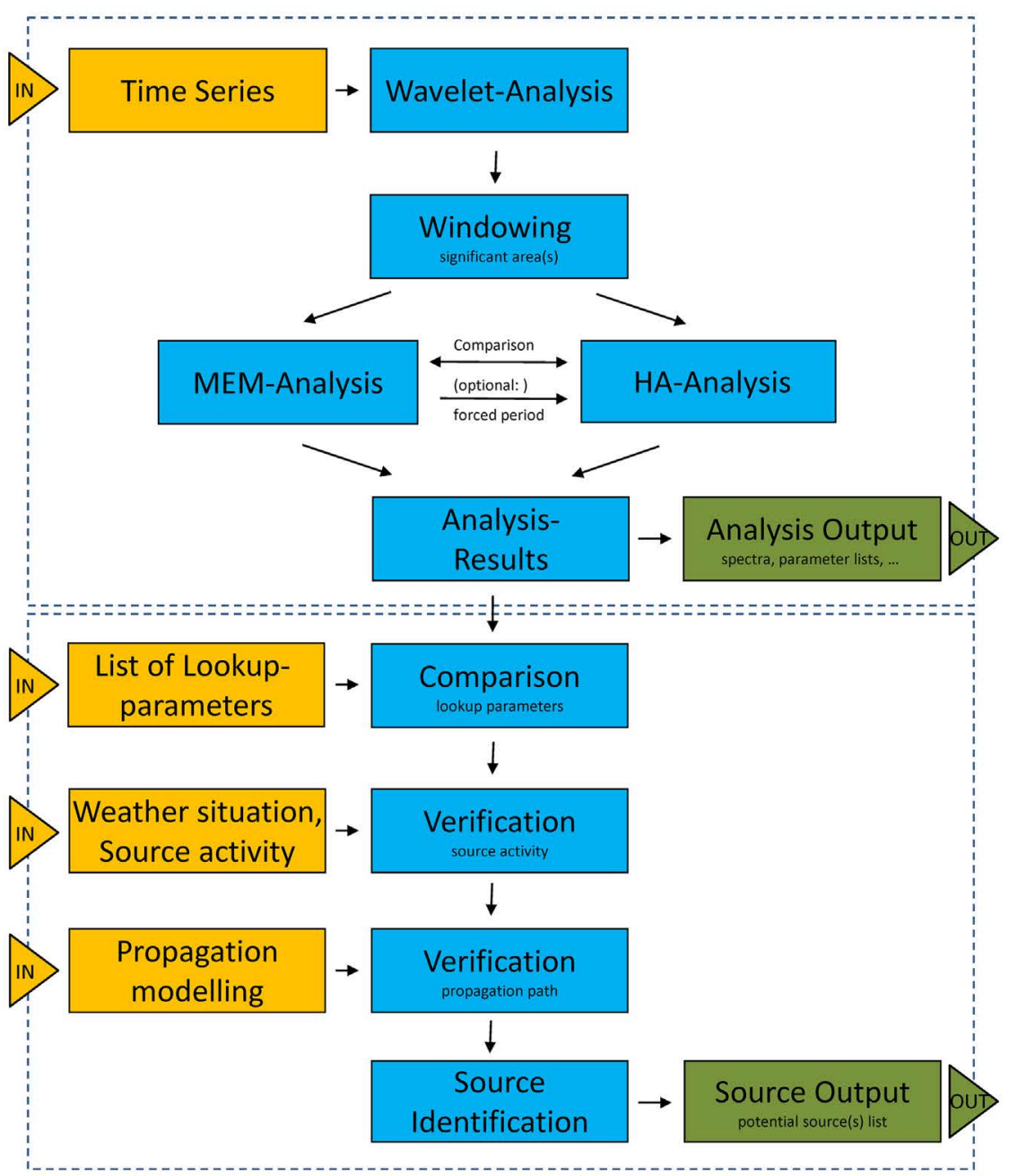

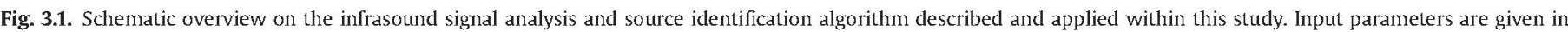

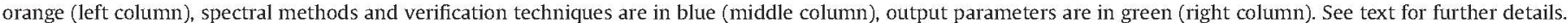
(For interpretation of the references to color in this figure legend, the reader is referred to the web version of this article.) 
analysis techniques to determine signal parameters as, e.g., wave period, amplitude, duration and uncertainty of identified signatures.

Comparisons to a lookup table of different infrasound sources and their individual signal parameters allow for the attribution of potential sources to the observed signatures. Further comparisons to nearby active sources of infrasound (e.g. severe weather systems or active volcanoes) are performed. Ray-tracing between potential sources of infrasound and observational fields of view can be performed to verify the source-to-receiver propagation of infrasound and thereby confirm the validity of this identification.

Fig. 3.1 gives a schematic overview on the procedures performed to analyse a given time series and potentially associate an infrasound source to the given results. It is applied to GRIPS 11,12 and 13 data in Section 4. The upper dashed box in Fig. 3.1 shows the spectral methods applied to the data, the lower dashed box highlights further procedures to confirm and associate the signal characteristics to a given source of infrasound.

The spectral analysis techniques involved include a wavelet analysis (WAV), a harmonic analysis (HA) and a maximum entropy method (MEM).

The wavelet technique used within this study is based on the software provided by Torrence and Compo (see Torrence and Compo, 1998). A Morlet mother wavelet function and a 95\% statistical significance test are used (see Bittner et al., 2010; Pilger et al., 2013 for details on the identification of wavelet signatures and their significance). The wavelet technique is
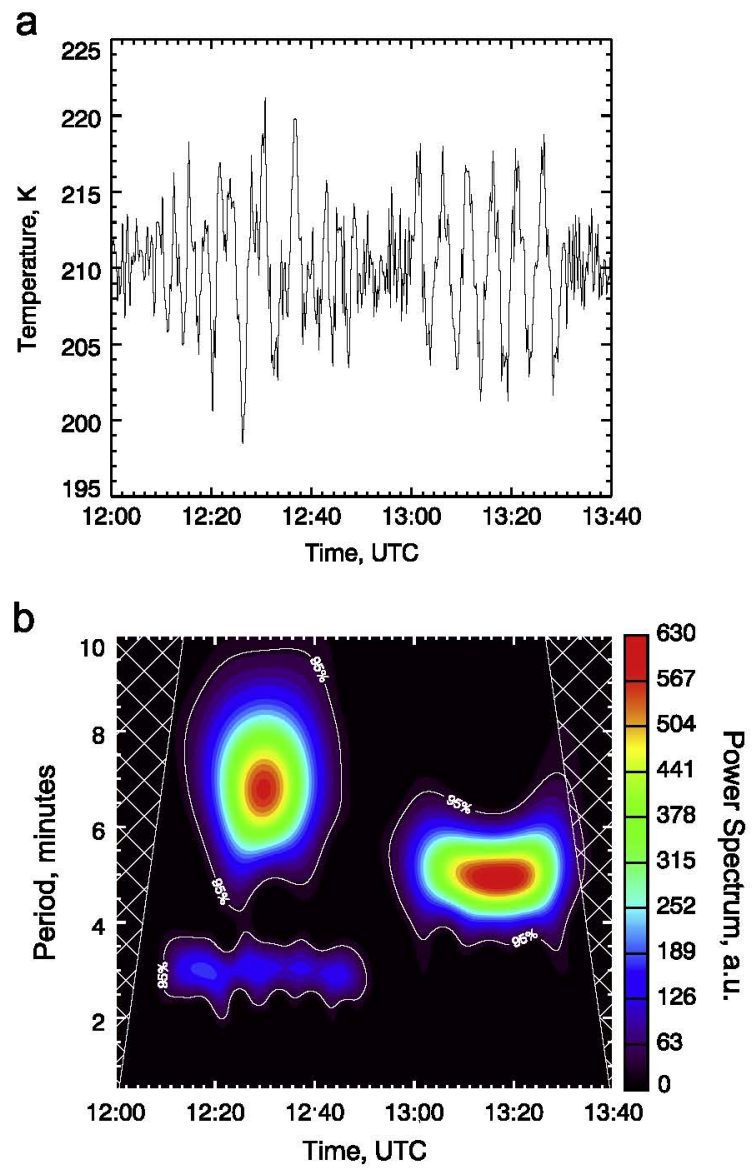

Fig. 3.2. Example time series of test data (left) and corresponding wavelet analysis (right). The time series shows $15 \mathrm{~s}$ temporal resolution temperature values containing transient 3,5 and $7 \mathrm{~min}$ period oscillations and random white noise. The wavelet analysis shows the power spectrum between periods of $30 \mathrm{~s}$ and 10 min. Areas of $95 \%$ significance are marked by a white line, hatched areas indicate potential edge effects of the analysis technique. an adequate method for the identification of infrasonic signatures in airglow time series, since it is able to locate transient, shortperiod and short-duration signatures in long time series. The method is thus used to initially identify points (and durations) in time, during which infrasonic activity is present and statistically significant in the time series. Furthermore a center period for the identified signature can be derived, thus allowing time and frequency dependent localization of a signal.

Fig. 3.2 shows a time series of test data and the corresponding wavelet analysis. Wave signatures of 3, 5 and $7 \mathrm{~min}$ are added to parts of the $100 \mathrm{~min}$ time series of random numbers and are unambiguously identified by the wavelet technique. Areas of significance and a cone of influence to exclude edge effects are indicated (for details, see Torrence and Compo, 1998). In a second step, these areas of significant infrasound activity are extracted as short duration time series details using a windowing approach. A time series fragment with the width of the wavelet derived significance in time is selected as new time series input for a second set of spectral analysis techniques (which do not have the good time resolution of the wavelet method).

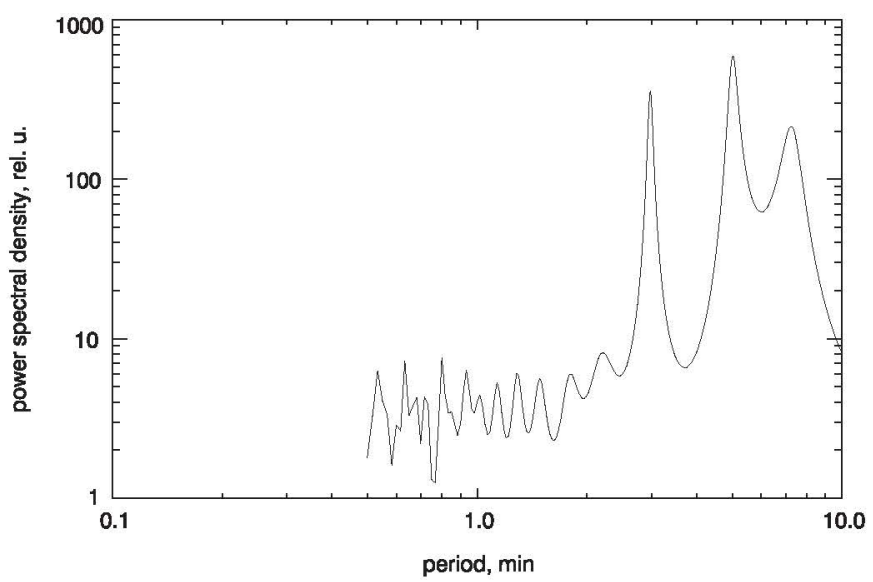

Fig. 3.3. Periodogram for the test data time series generated by the MEM. The period range between 0.5 and $10 \mathrm{~min}$ is shown with logarithmic scaling, the relative spectral intensity is highest (by more than one order of magnitude) for three distinct periods around 3,5 and $7 \mathrm{~min}$.

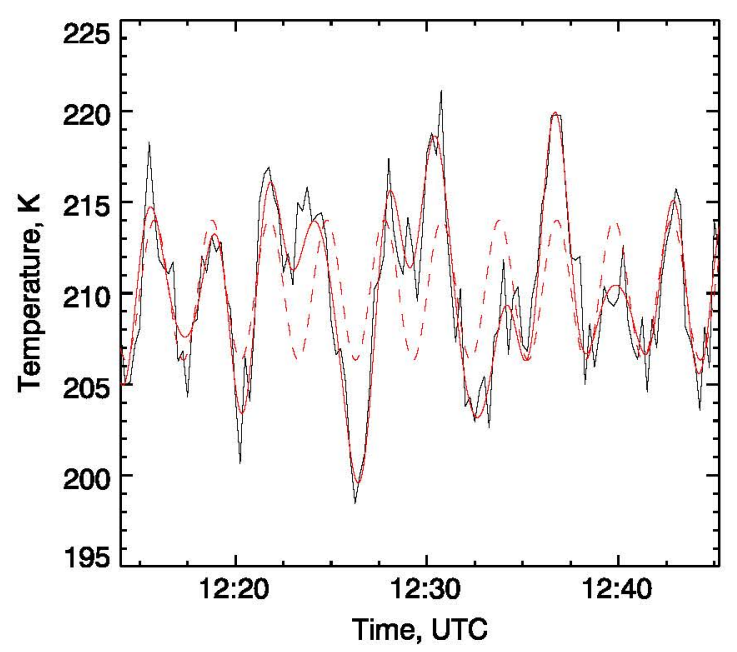

Fig. 3.4. Time series subset (black) with results of harmonic analysis approximation (red). The dashed line represents the approximation with one wave period of $3 \mathrm{~min}$, the solid red line represents an approximation with both, 3 and $7 \mathrm{~min}$ oscillations. (For interpretation of the references to color in this figure legend, the reader is referred to the web version of this article.) 
Table 3.1

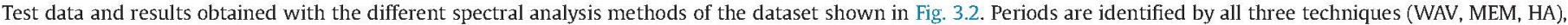
amplitudes are quantified by HA, duration is extracted from WAV significance.

\begin{tabular}{|c|c|c|c|}
\hline $\begin{array}{l}\text { Signature } \\
\text { (test data) }\end{array}$ & Period & Amplitude (K) & Duration \\
\hline No. 1 & $180 \mathrm{~s}(3 \mathrm{~min})$ & 4 & $40 \mathrm{~min}, 13$ wave trains \\
\hline No. 2 & $300 \mathrm{~s}(5 \mathrm{~min})$ & 6 & $30 \mathrm{~min}, 6$ wave trains \\
\hline No. 3 & $420 \mathrm{~s}(7 \mathrm{~min})$ & 5 & $20 \mathrm{~min}, 3$ wave trains \\
\hline Noise & white noise & 2 & \\
\hline \multicolumn{4}{|c|}{ observations } \\
\hline No. 1 & $182 \mathrm{~s}$ (WAV), $178 \mathrm{~s}$ (MEM), $180 \mathrm{~s}$ (HA) & 3.93 & $38 \mathrm{~min}, 13$ wave trains \\
\hline No. 2 & 297 s (WAV), 299 s (MEM), 299 s (HA) & 5.38 & $36 \mathrm{~min}, 7$ wave trains \\
\hline No. 3 & $409 \mathrm{~s}$ (WAV), $405 \mathrm{~s}$ (MEM), $416 \mathrm{~s}$ (HA) & 3.37 & $29 \mathrm{~min}, 4$ wave trains \\
\hline
\end{tabular}

Table 3.2

Lookup table of infrasonic sources and associated source parameters. It consists of period ranges (subdivided in the short-, medium- and long-period as well as the gravity wave range), amplitudes (in Kelvin, at mesopause altitude, see text for details) and signal durations ('singular' referring to fewer than 3 complete wave trains, 'continuous' referring to more).

\begin{tabular}{lcll}
\hline Source & Period & Amplitude (K) & Duration \\
\hline Severe weather & $<2 \mathrm{~s}(\mathrm{SP})$ & $<0.5$ & Continuous \\
& $2-60 \mathrm{~s}(\mathrm{MP})$ & $0.05-0.5$ & Continuous \\
& $60-300 \mathrm{~s}(\mathrm{LP})$ & $0.05-5$ & Continuous \\
Volcanic activity & $>300 \mathrm{~s}(\mathrm{GW})$ & $>0.5$ & Continuous \\
& $0.1-2 \mathrm{~s}(\mathrm{SP})$ & $0.05-5$ & Continuous \\
& $2-190 \mathrm{~s}(\mathrm{MP})$ & $>5$ & Continuous \\
Orography & $190-300 \mathrm{~s}(\mathrm{LP})$ & $>5$ & Singular \\
& $>300 \mathrm{~s}(\mathrm{GW})$ & $>5$ & Singular \\
Explosions & $20-60 \mathrm{~s}(\mathrm{MP})$ & $>0.05$ & Continuous \\
& $>300 \mathrm{~s}(\mathrm{GW})$ & $>0.5$ & Continuous \\
& $<20 \mathrm{~s}(\mathrm{SP} / \mathrm{MP})$ & $0.05-5$ & Singular \\
Microbaroms & $20-60 \mathrm{~s}(\mathrm{MP})$ & $>5$ & Singular \\
Earthquakes & $60-300 \mathrm{~s}(\mathrm{LP})$ & $>5$ & Singular \\
Aurorae & $5 \mathrm{~s}(\mathrm{MP})$ & $<0.5$ & Continuous \\
Meteorites & $0.5-2 \mathrm{~s}(\mathrm{SP})$ & $0.05-1$ & Continuous \\
Rocket starts & $10-60 \mathrm{~s}(\mathrm{MP})$ & $<0.5$ & Continuous \\
Thunder/Sonic boom & $1-5 \mathrm{~s}(\mathrm{SP} / \mathrm{MP})$ & $0.05-5$ & Singular \\
& $<2 \mathrm{~s}(\mathrm{SP})$ & $0.5-5$ & Singular \\
\hline
\end{tabular}

The maximum entropy method (see description in Wüst and Bittner, 2006) is applied to details of the temperature time series and it is able to return improved information about the periods contained within the data. Fig. 3.3 shows a MEM periodogram of the same test dataset between 0.5 and $10 \mathrm{~min}$. Although the MEM performs best when applied to time series of short duration (e.g. the wavelet-derived time series fragments), it also returns the periods of the 3,5 and 7 min signatures of the complete time series in good detail. After shortening the time series to a length in which at least one period is present over the complete duration, the MEM period detection and resolution is further improved.

The harmonic analysis (also see Wüst and Bittner, 2006) is a spectral analysis to fit one or more sinusoidal oscillations to a given time series and derive the periods, amplitudes and phases of a set of oscillations for a best least-square approximation. It can be applied to non-equidistant data or to data sets with a considerable amount of gaps, respectively. Fig. 3.4 shows the first half of the test dataset and the harmonic analysis of that dataset. Whereas the approximation with only one oscillation (dashed red line) resolves the shortest, $3 \mathrm{~min}$ oscillation within the time series, an approximation with more than one component (solid red line) also identifies the second, 7 min oscillation and gives a better approximation to the dataset (black line) combining two sinusoidal waves. The harmonic analysis furthermore quantifies with this approach the amplitude and phase of one or more wave components, which add up to a combination of oscillations best approximating the given time series.
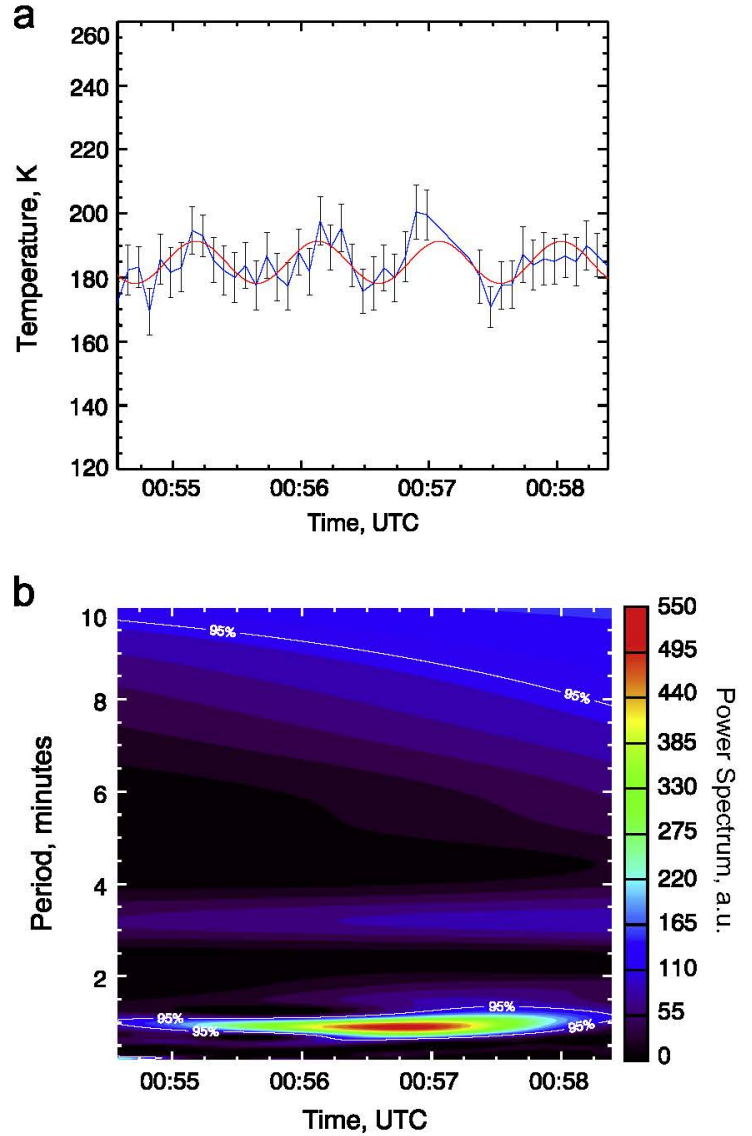

Fig. 4.1. Subset of GRIPS 13 temperature time series (left) and corresponding wavelet analysis (right) for the night of May 18th 2012, 00:54-00:58, UTC. The time series was recorded with $5 \mathrm{~s}$ temporal resolution. The course of derived temperatures is shown in blue with associated error bars in black and the result of the harmonic analysis in red. The wavelet analysis shows the respective power spectrum for periods between $10 \mathrm{~s}$ and $10 \mathrm{~min}$. Areas of $95 \%$ significance are marked by a white line. (For interpretation of the references to color in this figure legend, the reader is referred to the web version of this article.)

Both techniques, the MEM and the HA, are used to derive more precise information about the periods of the oscillations initially identified by the WAV. The MEM can be used to derive one or more signal components in a time series and provide these as start values for a harmonic analysis. A forced input for the HA period assures wave approximation to a given fixed period (e.g. an observed or source-typical specific period), whereas treating the period as free parameter allows the HA to identify the period on itself, like it does for amplitude and phase.

The periods, amplitudes and durations (in number of wave trains, extracted from the wavelet significance and resulting window width) of the spectrally identified components are given 
a

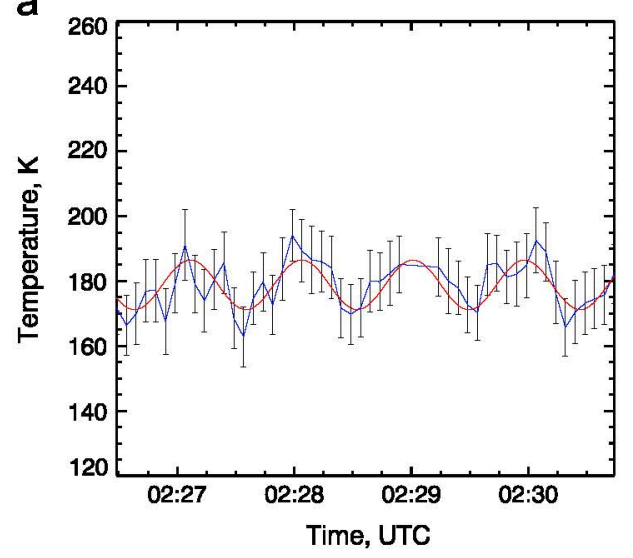

b

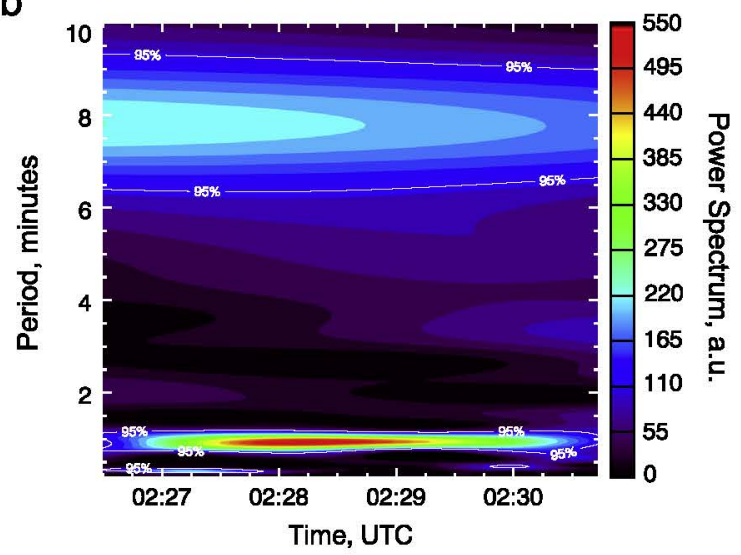

Fig. 4.2. Same as Fig. 4.1, but for May 18th 2012, 02:26-02:31, UTC. This wave signature exhibits similar parameters, but is observed more than $1 \mathrm{~h}$ later.

as resulting signal parameters for signal identification and for comparison to a lookup table (see Table 3.2 below). These parameters are further used to identify and associate a potential infrasound source to the observations.

Table 3.1 summarizes the test data example inputs and results identified by the spectral methods. The first ( $3 \mathrm{~min}$ ) oscillation is identified very well in period, amplitude and duration. The combination of the WAV method identifying significant signal durations with a windowing approach for MEM to quantify period and HA to quantify period and amplitude works very efficiently. The second ( $5 \mathrm{~min}$ ) oscillation is identified well in period, slightly overestimated in duration and thus slightly underestimated in amplitude. The third ( $7 \mathrm{~min}$ ) oscillation is slightly underestimated in period (although the combination of spectral methods optimizes the result with the final HA), overestimated in duration and thus underestimated in amplitude. The test case demonstrated that the approximation of the shortest-period oscillation was best, regardless of an interfering second oscillation with higher period and amplitude. The described combination of spectral analyses promises to be a good method for the intended use, the investigation of infrasonic wave periods below $5 \mathrm{~min}$ in mesopause temperature time series.

After applying spectral methods to a dataset, further methods are performed to identify and verify a source. First the signal parameters derived from spectral methods are compared to a list of lookup parameters, which associate certain combinations of period, amplitude and wave duration to different sources of infrasound. Table 3.2 shows a list of different infrasound sources and the signal parameters associated to them. It was generated during the course of the CESAR project by a comprehensive literature study (see Pilger, 2011 for references).
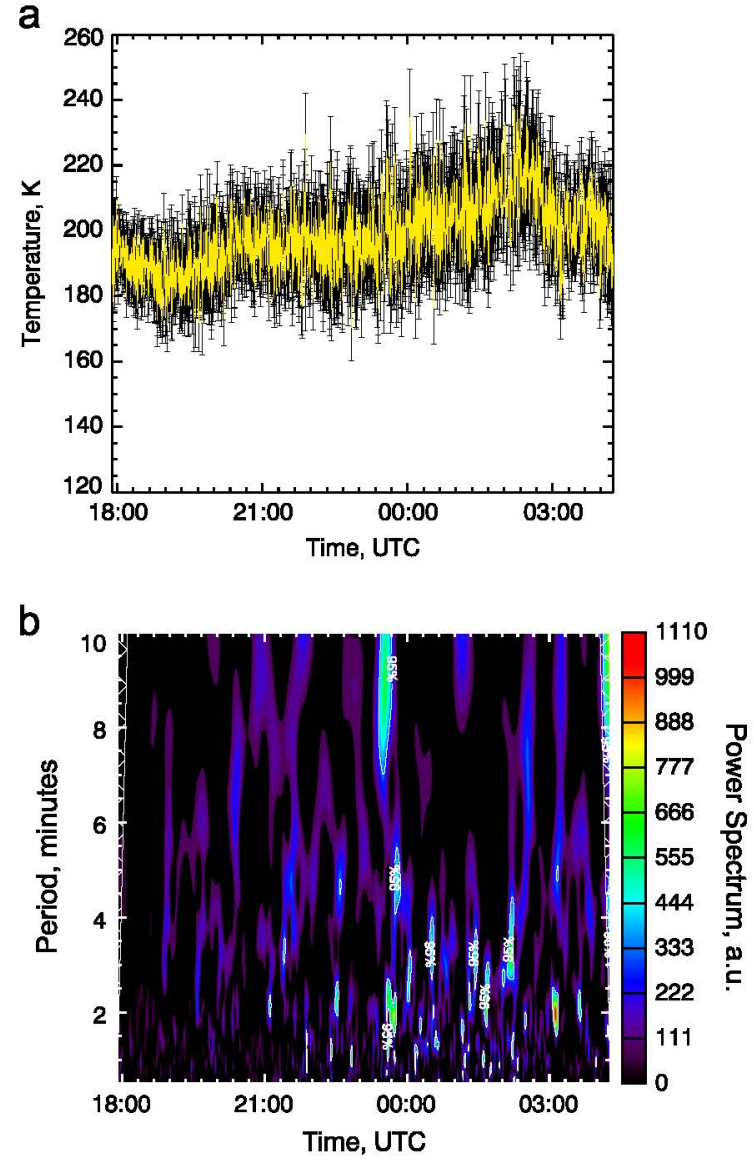

Fig. 4.3. Temperature time series (left) and corresponding wavelet analysis (right) for the GRIPS 11 instrument located near Mt. Etna with $15 \mathrm{~s}$ temporal resolution and the complete night from March 31st 2012, 17:55 UTC to April 1st 2012, 04:20 UTC. The course of derived temperatures is shown in yellow with associated error bars in black. The wavelet analysis (see Fig. 4.1) is derived for periods between $30 \mathrm{~s}$ and $10 \mathrm{~min}$. The reduced field of view of this instrument results in higher sensitivity to small scale structures. (For interpretation of the references to color in this figure legend, the reader is referred to the web version of this article.)

The period of an infrasonic source is normally given as period range, since distinct sources do not have one fixed period but fall within a certain range of periods (see e.g. Hedlin et al., 2002). Gravity wave periods (of known gravity wave sources) with periods $>300$ s have been added to the lookup table to give an indication of the upper period end and differentiation to the infrasound range.

Amplitudes in the lookup table are given in Kelvin and are reference values for vertical signal propagation of a (near-)surface source to the altitude of $87 \mathrm{~km}$ directly above the source. Amplitudes are given in this unit since temperature fluctuations are the parameter of observation using GRIPS airglow measurements. Typically infrasound pressure amplitudes are given in Pascal within a certain normalized source distance (e.g. $1 \mathrm{~Pa}$ at $1 \mathrm{~km}$ distance to the source). Pressure amplitudes are rangedependent parameters, they decrease with increasing distance depending on background temperature, wind and attenuation conditions (see e.g. Drob et al., 2003). The conversion from pressure to temperature amplitudes is described in Pilger and Bittner (2009). Exemplary source amplitudes of 1, 10 and $100 \mathrm{~Pa}$ pressure intensities at $1 \mathrm{~km}$ initial distance roughly correspond to $0.05,0.5$ and $5 \mathrm{~K}$ temperature fluctuations in the mesopause directly above the source. For increased horizontal and/or vertical distances between a source and a receiving field-of-view, infrasound propagation modelling (see below) has to be applied. 
a

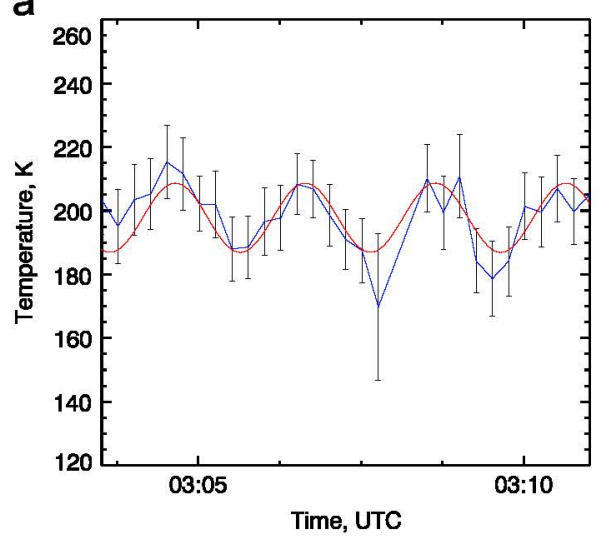

b

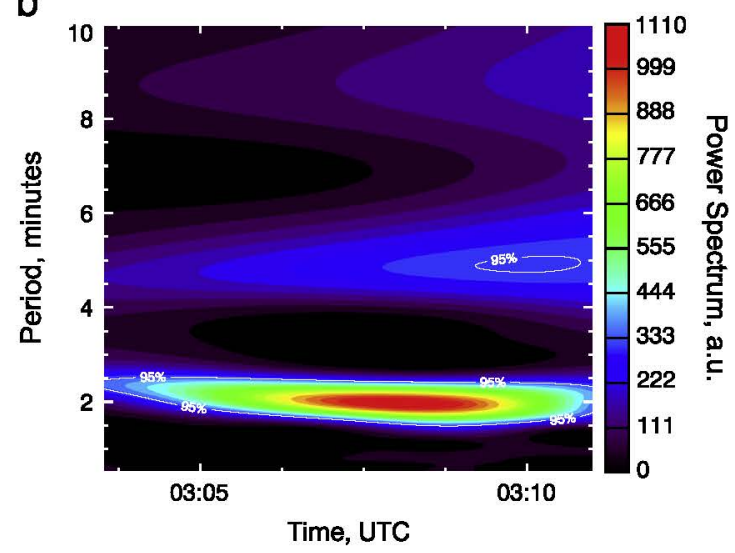

Fig. 4.4. Same as Fig. 4.1, but for a detail of the time series and the wavelet analysis shown in Fig. 4.3 between 03:04 UTC and 03:11 UTC.

During the second step in source identification the source activity is investigated. Meteorological conditions are therefore checked for severe weather sources and volcanic tremor is surveyed for signatures due to volcanic activity. This verification step is performed by reviewing ECMWF (European Center for Mediumrange Weather Forecasts) meteorological conditions and INGV volcanic activity information. The former is conducted by checking the ambient sea level pressure for low pressure and severe weather areas and by quantifying the frontal activity regarding equivalent potential temperature gradients in the vicinity of an observing site. The latter is conducted by checking for increased volcanic tremor activity indicating a volcanic paroxysm (see Section 4 for detailed examples on these verification procedures).

Finally propagation modelling can be applied to verify the propagation path between a source and a receiver. The infrasound propagation follows certain reflection and ducting patterns depending on the background temperature and wind fields of the atmosphere (e.g. see Georges and Beasley, 1977; Drob et al., 2003). Ray-tracing using the HARPA/DLR numerical model (Hamiltonian Ray-tracing Program for Acoustic Waves in the Atmosphere, further developed at DLR, see Pilger and Bittner, 2009) is performed to identify source to receiver paths of sound propagation and to quantify the intensity of a temperature fluctuation within the field of view for comparisons to observation (see Section 4 for an example on propagation modelling).

\section{Results and discussion}

Detections of infrasonic and short-period gravity wave signatures in airglow observations of different instruments are
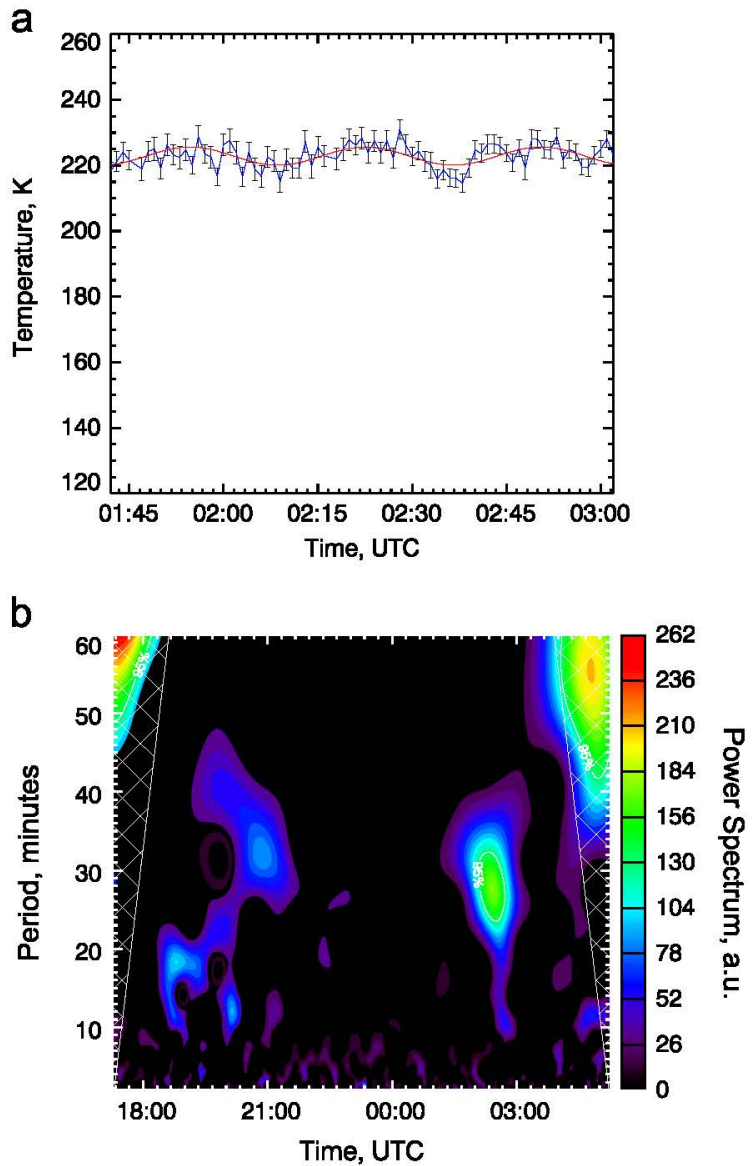

Fig. 4.5. Same as Fig. 4.1, but the high temporal resolution temperature time series (left) of the GRIPS 11 instrument was averaged to 1 min mean values for a better signal-to-noise ratio and display of the long period variation during February 9th 2012, 01:42-03:02 UTC. The power spectrum (right) shows the complete night from February 8 th 2012, 17:20 UTC to February 9th, 2012, 05:20 UTC and the period range between 2 and $60 \mathrm{~min}$. The only significant signature (outside the hatched edge-effect areas) is the one detailed on the left

performed using the combination of spectral analyses described in Section 3. The assignment of wave signatures to source activity of orographic, volcanic and meteorological origin is demonstrated for several cases and different sources in the following section.

\subsection{Mountain associated waves}

Infrasonic waves of orographic origin, so called Mountain Associated Waves (MAW) are continuous long-period oscillations in quasi-sinusoidal wave trains with a fixed centre period between 20 and 60 s (see e.g. Chimonas, 1977; Wilson and Olson, 2003). Observations of mountain associated infrasound are rendered possible by using the GRIPS 13 instrument with the highest available temporal resolution ( $5 \mathrm{~s}$ ) of the utilized airglow instruments within this study.

The GRIPS 13 mesopause field of view (see Section 2) is centred above Alpine ridge in Southern Germany/ Western Austria. It is thereby well located within a source region of orographic activity and fulfils the requirements for MAW detections.

Figs, 4.1 and 4.2 show two time series and corresponding wavelet analyses for the night from May 17th to 18th, 2012. Signatures with periods near/below 1 min over a number of wave trains are repeatedly observed during the night. The combination of the methods described above determines the signal parameters to be of $55 \mathrm{~s}$ period, 4 to $8 \mathrm{~K}$ amplitude with a duration of at 

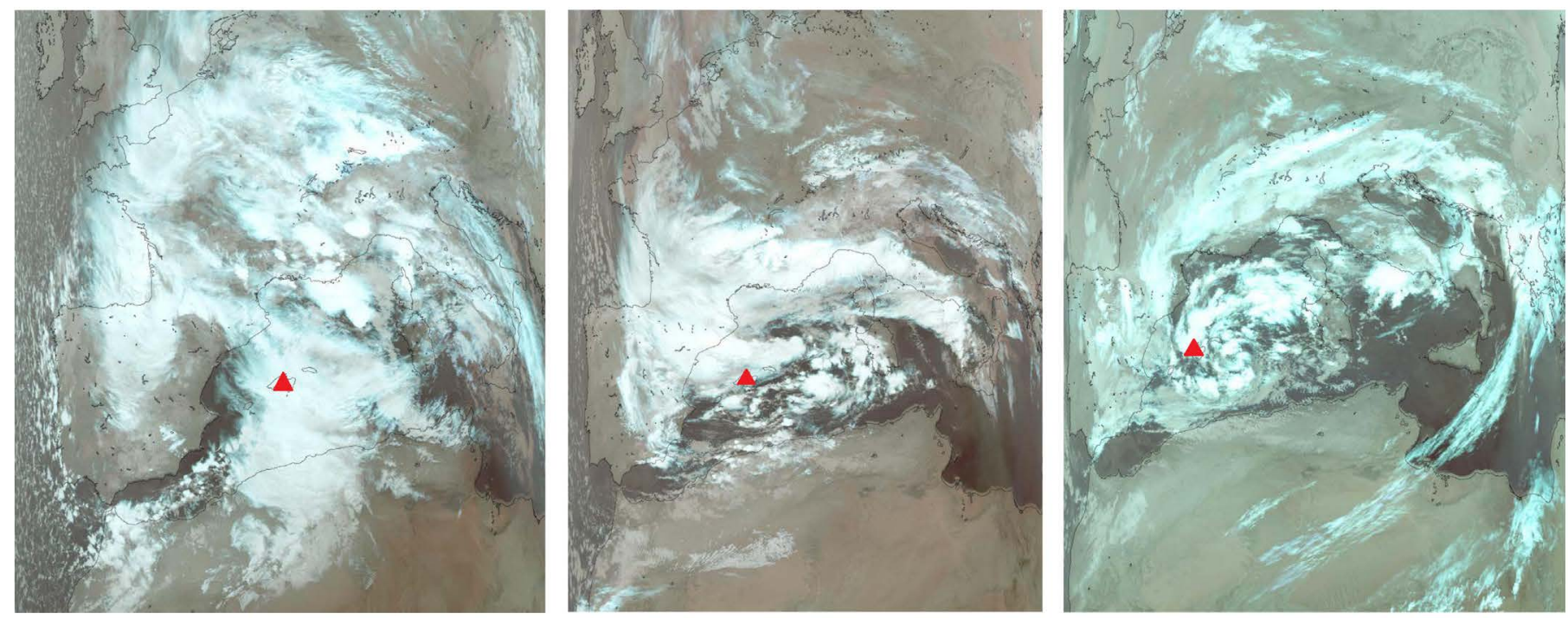

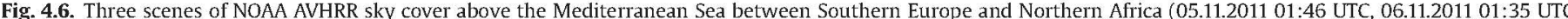

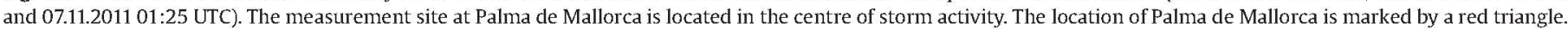

least 4 or more wave trains. The signal is therefore classified as a mountain associated waves according to Table 3.2.

\subsection{Volcanic activity}

The GRIPS 11 instrument was installed in Catania, Sicily with the field of view centred in the mesopause region directly above the Mt. Etna volcano. Although airglow spectrometers have been installed in the vicinity of active volcanoes (e.g. Hawaii, see Gardner, 1991 ; Hecht et al., 1995) in the past, this has to our knowledge been done for the first time attempting to observe signals in mesopause temperature time series related to volcanic wave activity.

Etna was very active during 2011/2012 and generated a series of at least 25 paroxysms (eruptive events with gas, lava and/or ash release). Since several of these eruptions took place after the installation of the instrument and during night-time, observations of potential airglow reactions to the volcanic activity were recorded and are presented.

Fig. 4.3 shows the GRIPS temperature time series and wavelet analysis of the night from 31st March to 1st April, 2012, when one of the Etna paroxysms took place during night-time. An increase in significant spectral activity was observed in the infrasound period range below 5 min during the second half of night. This is in good agreement with observations of volcanic tremor (pressure fluctuations of degassing magma, see McNutt, 1992), an indicator of volcanic activity recorded by the INGV, Catania. Increased volcanic tremor and collateral lava fountaining and ash emission begins to slowly increase during the evening of March 31st 2012 and peak between April 1st, 02:00 and 03:30, UTC, reaching a maximum of up to five orders of pressure magnitude above average around 03:00 UTC (also see the report of INGV about the "1 April 2012 paroxysm of Etna" to be found at www.ct.ingv.it ).

Fig. 4.4 shows a distinct wave signature observed between 03:05 and 03:10, UTC with a period of $2 \mathrm{~min}$. It accords well with the peak in volcanic activity and is very likely to be of volcanic origin.

The signal parameters derived by the spectral methods are a period of $120 \mathrm{~s}$, a large amplitude of $11 \mathrm{~K}$ and a duration of 4 wave trains, which is well in accordance for volcano related waves listed in Table 3.2.

A second period of nocturnal volcanic activity and a resulting paroxysm occurred in the night from February 8th to February 9th
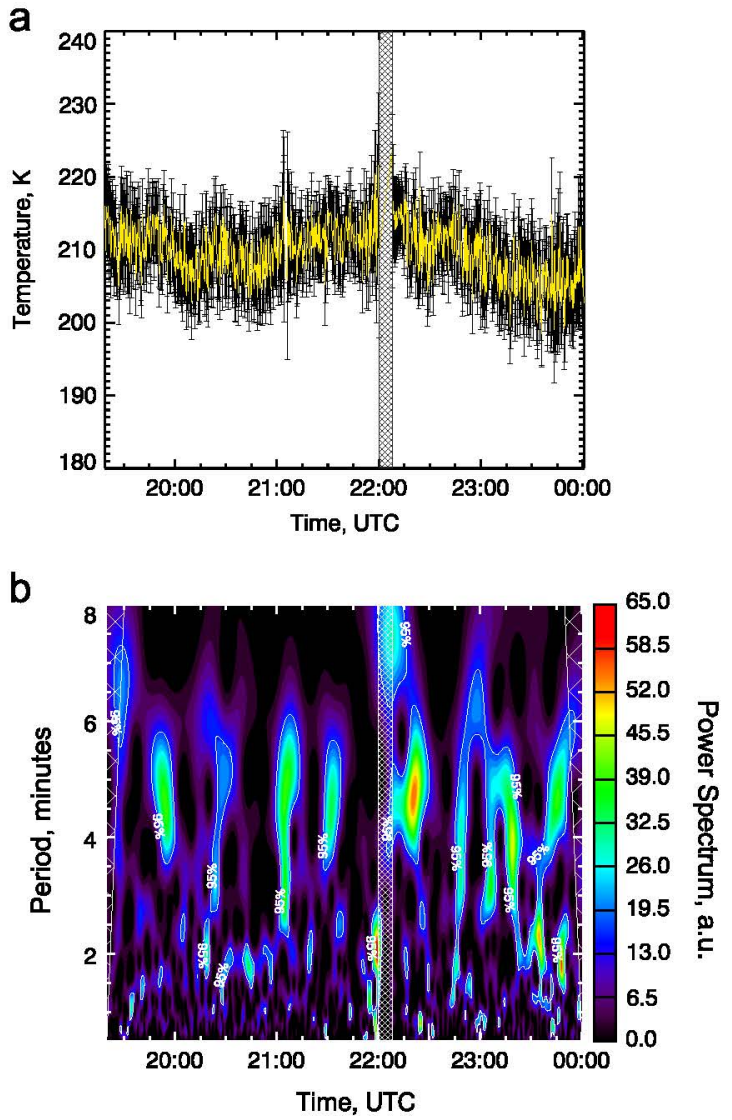

Fig. 4.7. Same as Fig. 4.3, but for the GRIPS 12 instrument with 15 s time resolution and a measurement episode of November 5th, 2011, 19:20 UTC to 00:00 UTC. A short data gap due to clouds is excluded from investigations (hatched area in the middle of the time series). Repeatedly observed signatures with periods between 3.5 and $5.5 \mathrm{~min}$ are clearly visible in the analysis during the complete measurement duration.

2012. Fig. 4.5 shows a time series detail with wave activity in the gravity wave period range above $5 \mathrm{~min}$. A clear and significant wave structure can be observed over a duration of $80 \mathrm{~min}$, which again corresponds well to increased volcanic tremor reported by INGV during this time. Contrary to the event from April 1st 2012 
a

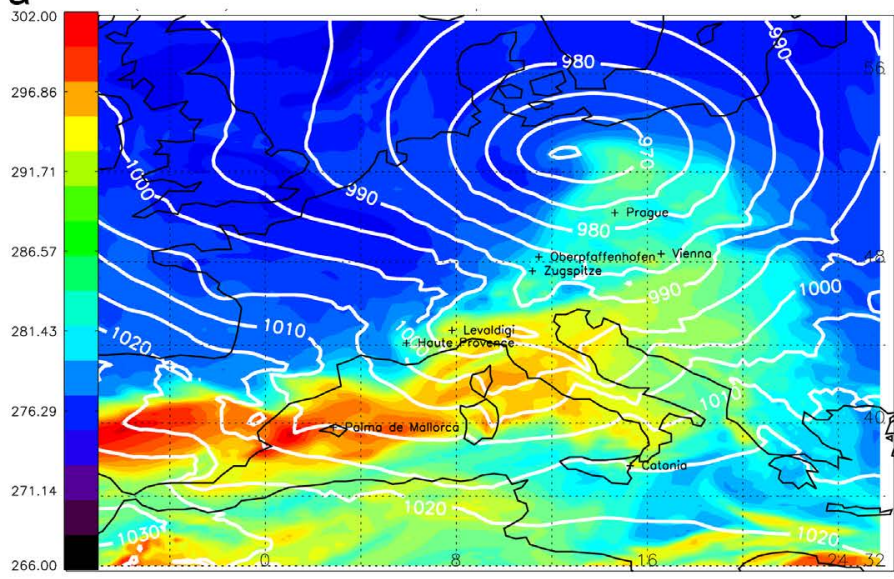

b

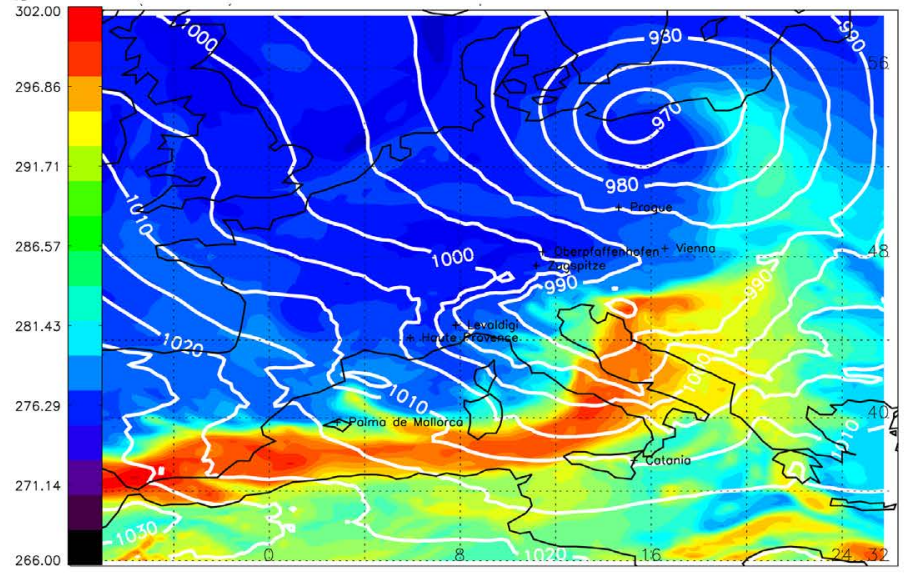

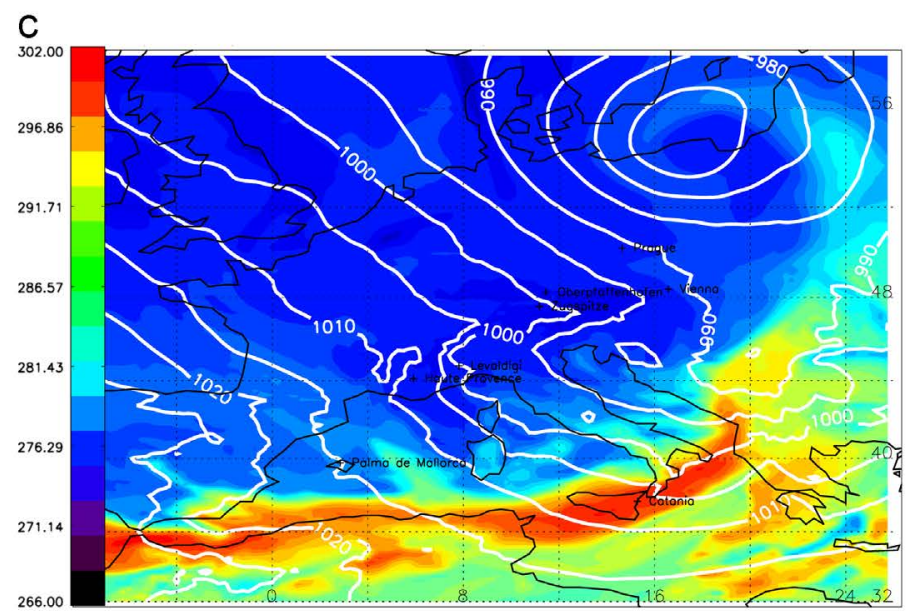

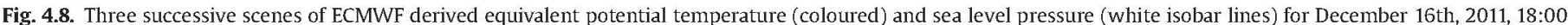

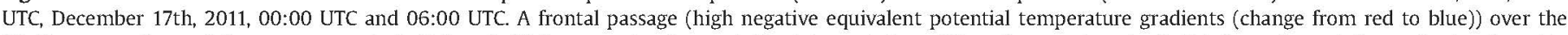

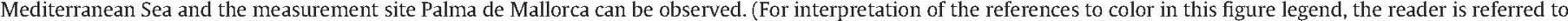
the web version of this article.)

the volcanic tremor activity increased more rapidly and stayed on a higher level over a longer period of time, the peak activity being reported for the time between February 9th, 00:30 UTC and 04:00 UTC. The peak tremor magnitude was of the same order of magnitude as for April 1st 2012 (see also report on the "9 February 2012 paroxysm of Etna" at www.ct.ingv.it).

The signal parameters are a period of $28 \mathrm{~min}$, amplitude of $5.5 \mathrm{~K}$ and duration of about $80 \mathrm{~min}$ between 01:42 UTC and 03:02 UTC. It is likely to be one of the first volcano-induced gravity waves observed in airglow, a gravity wave type, which has before been observed with ground-based instruments by e.g. Ripepe et al. (2010).

\subsection{Meteorological activity}

Infrasonic wave activity due to severe weather and storm systems was investigated during the CESAR measurement campaign in the Mediterranean area from September 13th, 2011 to January 10th, 2012. Nocturnal observations with the GRIPS 12 instrument installed at Palma de Mallorca, Spain, during the campaign were performed to investigate short period wave activity generated by severe weather events.

The first intense severe weather event investigated was a Mediterranean tropical storm between November 4th and November 9th, 2011 (FU Berlin's low pressure system "Rolf", NOAA identification "01M/99L"). Fig. 4.6 shows 3 scenes of the sky cover observed by NOAA's AVHRR (Advanced Very High Resolution Radiometer) satellite instrument for the Mediterranean Sea between November 5 th and November 7th, 2011, each for satellite overpass times around 01:25 UTC to 01:46 UTC, indicating a severe weather system centred above the observation site.

Despite the adverse conditions for optical observations during this event of heavy rainfall and dense cloud cover, observations were nevertheless carried out with the GRIPS 12 instrument every night. During the evening of November 5th, 2011 clouds cleared for several hours and allowed for continuous observations for $4.5 \mathrm{~h}$ between 19:20 UTC and 00:00 UTC. The temperature time series and corresponding wavelet analysis of this episode are shown in Fig. 4.7.

In spite of one short gap around 22:00 UTC, which excludes clear investigation of a 2 minute period spectral feature, the temperature time series is otherwise complete and shows a lot of spectral features in the long-period infrasound range. Apart from some further small 2 minutes period features, especially signatures with periods of 3.5 to $5.5 \mathrm{~min}$ are repetitively present in the complete time series. They correspond well to MLTI (mesosphere, lower thermosphere, ionosphere) observations of longperiod infrasound due to convective severe weather sources reported in literature (Georges, 1973; Blanc, 1985; Walterscheid et al., 2003; Sindelarova et al., 2009). The strongest signature exhibits a centre period of $4.5 \mathrm{~min}$ with $2.8 \mathrm{~K}$ amplitude and is observed at 22:20 UTC, shortly after the gap. This further 

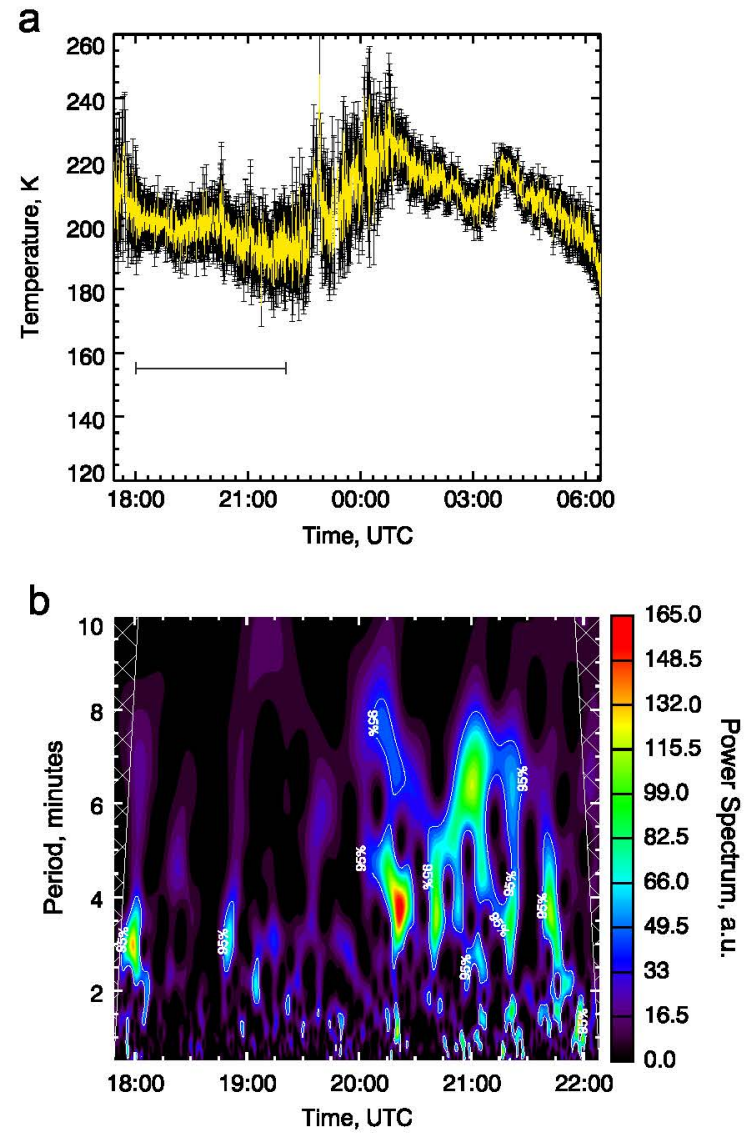

Fig. 4.9. Same as Fig. 4.3, but for a complete nocturnal time series of the GRIPS 12 instrument during the night from December 16th, 2011 to December 17th, 2011. Wavelet spectral analysis is only performed between 17:50 UTC and 22:10 UTC (area indicated by a horizontal bar in the left panel). A cluster of 3 to $6 \mathrm{~min}$ period signatures starts around 20:10 UTC (see text for details).

strengthens the conclusion that severe weather activity (associated with the observed cloudiness) also convectively generates infrasonic wave signatures.

A second period of meteorological activity investigated is a frontal passage at Palma de Mallorca during the night of December 16 th to 17 th, 2011. Since a frontal system is also defined by convective activity, infrasound is generated by this weather phenomenon as well. Fig. 4.8 shows the frontal passage over the measurement site in three successive scenes separated by $6 \mathrm{~h}$ between December 16th, 18:00 UTC and December 17th, 06:00 UTC. The plots are derived from ECMWF data of mean sea level pressure and $850 \mathrm{~h} \mathrm{~Pa}$ equivalent potential temperature (calculated from $850 \mathrm{~h}$ Pa temperature and relative humidity, see e.g. Bolton, 1980). They show the passage of a frontline, visible in strong gradients of equivalent potential temperature (from red to blue in Fig. 4.8), which is north of Palma in the first, above Palma in the second and south of Palma in the third scene. Fig. 4.9 (left panel) shows the corresponding GRIPS temperature time series for that night from 18:00 UTC to 06:00 UTC. The passage of the frontline can be anticipated between 22:00 UTC and 01:00 UTC, when the recorded temperatures increase. In this study the focus is laid on the question, whether the convective activity related to the frontal system leads to the generation of infrasonic waves detectable in airglow before the actual arrival of the front. Therefore only the first hours of the evening of December 16th from 18:00 UTC to 22:00 UTC are spectrally analyzed.

Fig. 4.9 (right panel) shows the wavelet analysis from 18:00 UTC to 22:00 UTC. Spectral features are rare until 20:00 UTC, followed by a series of significant features in the infrasound period range. A distinct signature with $3.5-4 \mathrm{~min}$ period and $3.4 \mathrm{~K}$ amplitude is observed from $20: 10$ to $20: 30$ UTC. It is the start to a series of signatures indicating increased wave activity presumably generated by the nearby front. The front itself passes the measurement site some hours later, increasing the cloud coverage and so the uncertainty of the data around midnight.

In order to verify, that the observed increase in wave activity is associated with the arrival of waves originating at the frontal line convection, propagation modelling is applied. Fig. 4.10 shows an infrasound propagation pattern for the meteorological conditions of December 16th, 2011, 20:00 UTC. ECMWF numerical weather forecast temperature and wind data are used for this case in combination with MSISE-00 and HWM-07 (see Picone et al., 2002; Drob et al., 2008) climatological data. The source is assumed to be at $12 \mathrm{~km}$ altitude (generation of convection at the tropopause level) and at the coordinates $41.15^{\circ} \mathrm{N}, 2.15^{\circ} \mathrm{W}$ (location at the coastline near Barcelona, where the front is nearest to Palma de Mallorca at 20:00 UTC). The azimuthal direction of propagation is $168^{\circ}$ (clockwise direction from north), so that rays from the source region pass the centre of the GRIPS 12 field of view above Palma de Mallorca in $\sim 190 \mathrm{~km}$ distance (as indicated in the figure).

The propagation pattern shows stratospheric and thermospheric ducting features. The passage of a focused duct of rays reflected from thermospheric altitudes $(\sim 120-140 \mathrm{~km})$ is well recognizable within the instrument's field of view. The rays within this duct have a total travel distance of $\sim 240-270 \mathrm{~km}$ from the source and a travel time of $12-15 \mathrm{~min}$, thus arriving at $\sim 20: 15$ UTC in the field of view and corresponding well to the most intense signature in Fig. 4.9.

For greater distances (the front is still above the mainland before 20:00 UTC), only few rays (and no focused duct) pass the field of view. A significantly reduced number of signatures are observed in the field of view. If the source is nearer (approaching front later than 20:00 UTC) the field of view is passed by rays directly emitted from the source (although without a focused duct). The modelled temperature fluctuations (starting with a convective source intensity of $100 \mathrm{~Pa}$ ) are in the order of 1.5 to $3.5 \mathrm{~K}$ in the field of view, which is in good agreement to the observed $3.4 \mathrm{~K}$ signature for the first strong signature recorded at 20:15 UTC in Fig. 4.9.

The propagation modelling is thereby able to support the observation of infrasonic wave signatures by the approaching frontal convection of December 16th, 2011 at Palma de Mallorca. The most intense wave activity signature can be explained by focusing and ducting of sound rays reflected from the thermosphere and passing the instrument's field of view around 20:15 UTC.

\section{Summary and outlook}

A method to identify short period atmospheric wave signatures within the infrasonic and gravity wave regime and the respective attribution to probable sources in airglow observations is presented within this study. A combination of spectral analysis techniques to determine wave parameters in time series of $\mathrm{OH}$ rotational temperatures is compared to infrasound lookup parameters and verified considering additional parameters for source activity and propagation modelling. The successful application of this method is presented in case studies for three different observation sites and three different kinds of infrasound sources. Orographic, volcanic and meteorological source activity is observed within the infrasonic and short period gravity wave period range and presented for these cases.

The spectral analysis techniques used within this study are Wavelet Analysis, the Maximum Entropy Method and Harmonic 


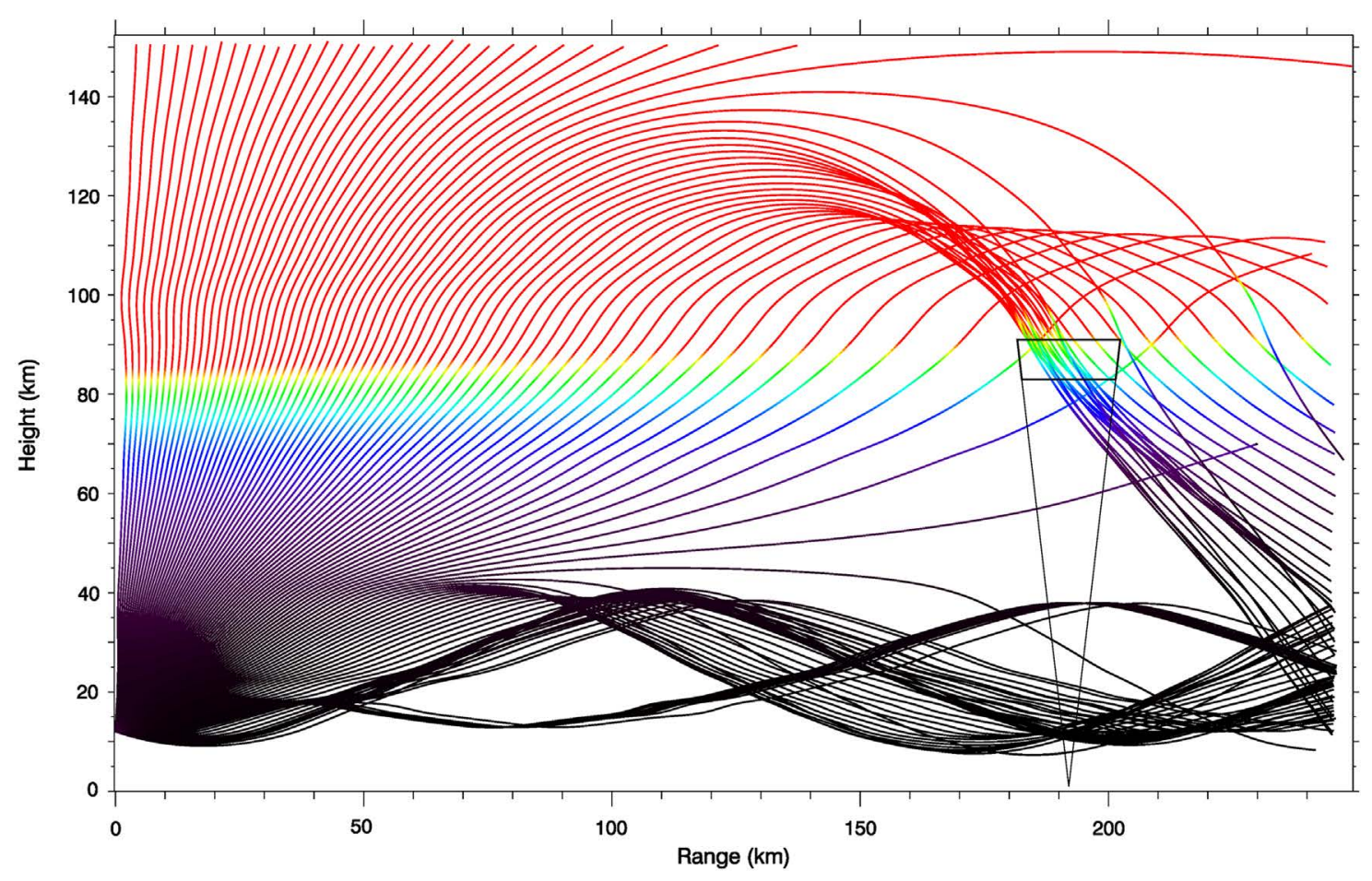

Temperature Fluctuations ( $K$ )

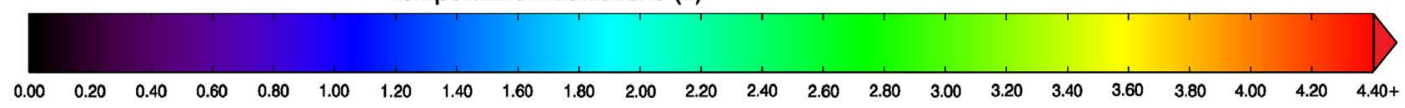

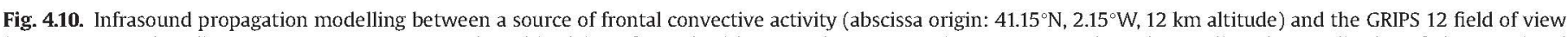

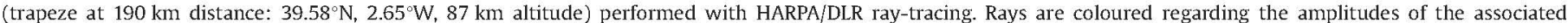

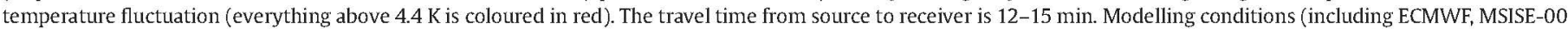

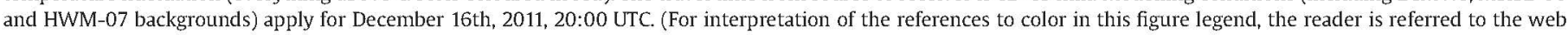
version of this article.)

Analysis. The temporal resolution of the wavelet technique allows for identifying fluctuations as actual wave signatures at $95 \%$ significance level in time and frequency space. Thus interesting time periods can be studied in greater detail with the other techniques. The combination of the methods results in the derivation of a list of signal parameters (such as onset time, duration, period and amplitude) associated with significant events in the time series. Potential sources of infrasound are then identified by comparing the observed signal parameters to a lookup list of expected parameters derived from an extensive literature study. Although there is a certain overlap of signal parameters (e.g. in period and amplitude ranges) for different sources, identification of unambiguous infrasound sources is possible for certain outstanding signatures are presented within this study. Identification of weaker, less clearly detectable signatures on the other hand may result in ambiguous source identification and needs further source verification procedures (see Figure 3.1).

Orographic infrasound is generated by airflow over mountain ranges. These so-called "Mountain Associated Waves" with a typical period distribution around 20-60 s have been observed by a GRIPS spectrometer above the European Alps in Southern Germany/ Western Austria. The detection of orographically generated waves in mesopause altitudes was performed using observations with a high temporal resolution of $5 \mathrm{~s}$.

Volcanic infrasound (and also short period gravity wave) signatures in airglow observations have been detected using a GRIPS instrument with its field of view centred above Mt. Etna crater on Sicily during the paroxysmal activity in 2011/2012. Wave signatures during episodes of eruptive volcano activity were identified in nocturnal observations of $\mathrm{OH}$ airglow and correspond well to well-defined increases in volcanic tremor activity reported by the INGV. Two cases with wave periods of 2 min (infrasound) and $28 \mathrm{~min}$ (gravity wave) match in time with the peaks of volcanic activity. To our knowledge these are the first direct detections of infrasonic and gravity wave signatures in airglow related to volcanic activity.

Meteorological infrasound generated by storm systems and frontal activity was identified during severe weather conditions during the CESAR observation campaign in 2011/2012. GRIPS airglow observations were performed to identify and quantify severe weather wave signatures in the infrasound and gravity wave period range. Two strong events of severe weather in four campaign months were identified and confirmed by numerical weather forecast data and satellite observations. The generation of infrasonic waves by a Mediterranean tropical storm (in the beginning of November 2011) and by a frontal passage (in midDecember 2011) over the GRIPS observation site at AEMET, Palma de Mallorca was detected in $\mathrm{OH}$ airglow temperatures. Signatures are situated in the long-period infrasound range of 3-5 min, corresponding well to reports of long period infrasound generated by severe weather in the literature. The propagation of infrasound from a meteorological source to the instrument's field of view was confirmed by ray-tracing using the HARPA/DLR numerical model. While the detection by only one instrument does not allow directional information (e.g. triangulating a source), the onset time, duration and source parameters of the source in this case quite well confirm the source verification by propagation modeling. An increased number of detections by combined or multidimensional instruments (e.g. 2-dimensional airglow imagers or 
3-airglow-instrument-arrays) would nevertheless be very useful for future infrasound source identification.

The observation and investigation of infrasound and gravity wave signatures by different sources in airglow measurements will be continued and intensified using the NDMC as a growing network of observation sites all around the world.

\section{Acknowledgements}

The work within this study was performed in close cooperation between the University of Augsburg (UNA) and the German Aerospace Center (DLR) during the projects CESAR ("Charakterisierung des differentiellen Energiegehaltes von Vb-Zyklonen über die Quantifizierung abgestrahlter Schwere- und Infraschallwellen in der Atmosphäre") and ARISE (Atmospheric dynamics Research InfraStructure in Europe).

The authors kindly acknowledge the CESAR project funding of the Bavarian State Ministry for Environment and Health (BayStMUG), Grant no. ZKL01Abt7_18459, and the ARISE project funding by the European Union under the 7th Framework Programme (EU-FP7), Grant no.284387.

The authors thank the INGV (Istituto Nazionale di Geofisica e Vulcanologia, Sezione di Catania) for their helpful support in hosting an airglow instrument and providing information on volcanic activity.

The authors thank the AEMET (Agencia Estatal de Meteorologia, Palma de Mallorca) for their helpful support during an airglow and radiosonde measurement campaign.

Data management and data availability is provided by the WDC-RSAT (World Data Center for Remote Sensing of the Atmosphere, http://wdc.dlr.de).

Airglow observations and infrasound research within this study are performed in the context of the NDMC (Network for the Detection of Mesosphere Change, http://wdc.dlr.de/ndmc).

\section{References}

Baker, D.J., Stair Jr., A.T., 1988. Rocket measurements of the altitude distributions of the hydroxyl airglow. Physica Scripta 37, 611-622.

Bates, D.R., Nicolet, M., 1950. Atmospheric hydrogen. Publications of the Astronomical Society of the Pacific 62 (365), 106-110.

Bittner, M., Höppner, K., Pilger, C., Schmidt, C., 2010. Mesopause temperature perturbations caused by infrasonic waves as a potential indicator for the detection of tsunamis and other geo-hazards. Natural Hazards and Earth System Sciences $10,1431-1442$.

Blanc, E., 1985. Observations in the upper atmosphere of infrasonic waves from natural or artificial sources-a summary. Annales Geophysicae 3, 673-687.

Bolton, D., 1980. The computation of equivalent potential temperature. Monthly Weather Review 108, 1046-1053.

Chimonas, G., 1977. A possible mechanism for mountain-associated infrasound. Journal of the Atmospheric Sciences 34, 806-811.

Christie, D.R., Campus, P., 2010. The IMS infrasound network: design and establishment of infrasound stations, Infrasound Monitoring for Atmospheric Studies. Springer, Germany, Heidelberg.

Drob, D.P., Picone, J.M., Garcés, M., 2003. Global morphology of infrasound propagation. Journal of Geophysical Research 108, 4680-4691.

Drob, D.P. Emmert, J.T. Growley, G., Picone, J.M. Shepherd, G. G. Skinner, W., Hays, P., Niciejewski, R.J., Larsen, M., She, C.Y., Meriwether, J.W., Hernandez, G., Jarvis, M.J., Sipler, D.P., Tepley, C.A., O'Brien, M.S., Bowman, J.R., Wu, Q., Murayama, Y.,
Kawamura, R.A., Reid, I.M., Vincent, R.A., 2008. An empirical model of the Earth's horizontal wind fields: HWM07. Journal of Geophysical Research 113 , 12304-12321.

Gardner, C.S., 1991. Introduction to ALOHA-90: The airborne lidar and observations of the Hawaiian Airglow Campaign. Geophysical Research Letters 18 (7), $1313-1316$.

Georges, T.M., 1973. Infrasound from convective storms: examining the evidence Review of Geophysics and Space Physics 11 (3), 571-594.

Georges, T.M., Beasley, W.H., 1977. Refraction of infrasound by upper-atmospheric winds. Acoustical Society of America Journal 61, 28-34.

Gossard, E.E., Hooke, W.H., 1975. Waves in the Atmosphere: Atmospheric Infrasound and Gravity Waves-Their Generation and Propagation. Elsevier, USA New York.

Hecht, J.H., Ramsay Howat, S.K., Walterscheid, R.L., Isler, J.R., 1995. Observations of variations in airglow emissions during ALOHA-93. Geophysical Research Letters $22(20), 2817-2820$.

Hedlin, M.A.H., Garcés, M., Bass, H., Hayward, C., Herrin, G., Olson, J., Wilson, C., 2002. Listening to the secret sounds of Earth's atmosphere. EOS Transactions 83 (557), 564-565.

Jones, R.M., E.S. Gu, A.J. Bedard Jr., 2004. Infrasonic atmospheric propagation studies using a 3-D ray trace model. In: Proceedings of the 22nd Conference on Severe Local Storms, Hyannis, MA, 4-8 October P29, American Meteorological Society

Khomich, V.Yu., Semenov, A.I., Shefov, N.N., 2008. Airglow as an Indicator of Upper Atmospheric Structure and Dynamic. Springer, Germany, Heidelberg.

Le Pichon, A., Vergoz, J., Blanc, E., Guilbert, J., Ceranna, L., Evers, L., Brachet, N., 2009 Assessing the performance of the International Monitoring System's infrasound network: Geographical coverage and temporal variabilities. Journal of Geophysical Research $114,8112-8126$.

Le Pichon, A., Blanc, E., Hauchecorne, A., 2010. Infrasound Monitoring for Atmospheric Studies. Springer, Germany, Heidelberg.

McNutt, S.R., 1992. Volcanic Tremor. Encyclopedia of Earth System Science. Academic Press, San Diego, California, pp. 417-425.

Meinel, A.B., 1950. OH emission bands in the spectrum of the night sky Part II. Astrophysics Joumal, 112; pp. 120-130.

Pendleton, W.R., Espy, P.J., Hammond, M.R., 1993. Evidence for non-localthermodynamic-equilibrium rotation in the $\mathrm{OH}$ nightglow. Journal of Geophy sical Research 98, 11567-11579.

Picone, J.M., Hedin, A.E., Drob, D.P., Aikin, A.C., 2002. NRLMSISE-00 empirical model of the atmosphere: statistical comparisons and scientific issues. Journal of Geophysical Research 107, 1468-1483.

Pilger, C., Bittner, M., 2009. Infrasound from tropospheric sources: impact on mesopause temperature? Journal of Atmospheric and Solar-Terrestrial Physics, 71. pp. 816-822.

Pilger, C., 2011. Modellierung von infraschall in der atmosphere: Auswirkungen auf die Mesopausentemperatur. DLR-Forschungsbericht. (2011-20, 133p, in german).

Pilger, C., Schmidt, C., Bittner, M., 2013. Statistical analysis of infrasound signatures in airglow observations: indications for acoustic resonance. Journal of Atmospheric and Solar-Terrestrial Physics 93, 70-79.

Ripepe, M., De Angelis, S., Lacanna, G., Voight, B., 2010. Observation of infrasonic and gravity waves at Soufrière Hills Volcano, Montserrat. Geophysical Research Letters 37, 1-5. (LOOE14)

Schmidt, C., Höppner, K. Bittner, M., A Ground-Based 2013. Spectrometer Equipped with an InGaAs Array for Routine Observations of $\mathrm{OH}(3-1)$ Rotational Temperatures in the Mesopause Region Joumal of Atmospheric and Solar-Terrestrial Physics 102, 125-139.

Sindelarova, T., Buresova, D., Chum, J., Hruska, F., 2009. Doppler observations of infrasonic waves of meteorological origin at ionospheric heights. Advances in Space Research 43, 1644-1651.

Torrence, C., Compo, G.P., 1998. A practical guide to wavelet analysis. Bulletin of the American Meteorological Society 79, 61-78.

Walterscheid, R.L., Schubert, G., Brinkman, D.G., 2003. Acoustic waves in the upper mesosphere and lower thermosphere generated by deep tropical convection. Journal of Geophysical Research 108 (A11), 1392.

Wilson, CR, Olson, JV, 2003. Mountain associated waves at I53US and 155US in Alaska and Antarctica in the frequency Passband from 0.015 to $0.10 \mathrm{~Hz}$ InfraMatics 3, 6-10.

Wüst, S., Bittner, M., 2006. Non-linear resonant wave-wave interaction (triad): case studies based on rocket data and first application to satellite data. Journal of Atmospheric and Solar-Terrestrial Physics 68, 959-976. 